\title{
Obstructive Sleep Apnea Syndrome in Children with Mucopolysaccharidoses II (Hunter Syndrome)
}

\author{
A. A. Baranov, L. S. Namazova-Baranova, N. D. Vashakmadze, A. K. Gevorkyan, \\ L. M. Kuzenkova, T. V. Podkletnova, O. V. Kozhevnicova, B. B. Altunin \\ Scientific Centre of Children Health under the Russian Academy of Medical Sciences, Moscow, \\ Russian Federation \\ Email: nato-nato@yandex.ru
}

Received 3 June 2015; accepted 23 June 2015; published 29 June 2015

Copyright (C) 2015 by authors and OALib.

This work is licensed under the Creative Commons Attribution International License (CC BY). http://creativecommons.org/licenses/by/4.0/

C. (i) Open Access

\section{Abstract}

In order to assess the prevalence and dynamics of changes of basic parameters of obstructive sleep apnea syndrome (OSAS) at mucopolysaccharidoses II (MSP II) cardiorespiratory monitoring was performed for 17 children. Slight OSAS (apnoea-hypopnoea index (AHI) was 1.5 - 5) was diagnosed in 4 patients $(23.5 \%)$, moderate OSAS (AHI was 5 - 10) -in 4 patients $(23.5 \%)$, severe OSAS (AHI was higher than 10)-in 2 patients (11.8\%). AHI median at Hunter syndrome was $5.3 \pm$ 6.9/ hour. In the group of infants ( 1 - 3 years old) slight OSAS (AHI is $0.8 \pm 0.3 / \mathrm{h}$ ) dominated, whereas in the group of teenagers-sever OSAS (AHI is $10.9 \pm 9.4 / \mathrm{h}$ ), a median of blood saturation with oxygen $\left(\mathrm{SpO}_{2}\right)$ was $87.5 \pm 10.6 \%$, desaturation index (DI) $-10.4 \pm 13.3 /$ hour. On the whole, OSAS was diagnosed in $58.8 \%$ of children and increased with increasing of the disease severity. Thus cardiorespiratory monitoring is necessary for revealing children with moderate and moderate-to-severe OSAS, followed by prevention of life-threatening conditions, the occurrence of which is possible at this syndrome.

\section{Keywords}

Hunter Syndrome, Mucopolysaccharidoses, Cardiorespiratory Monitoring, Obstructive Sleep Apnea Syndrome

Subject Areas: Pediatrics

\section{Introduction}

Respiratory pathology and related disorders of breathing mechanism can lead to serious consequences and are a

How to cite this paper: Baranov, A.A., Namazova-Baranova, L.S., Vashakmadze, N.D., Gevorkyan, A.K., Kuzenkova, L.M., Podkletnova, T.V., Kozhevnicova, O.V. and Altunin, B.B. (2015) Obstructive Sleep Apnea Syndrome in Children with Mucopolysaccharidoses II (Hunter Syndrome). Open Access Library Journal, 2: e1630. http://dx.doi.org/10.4236/oalib.1101630 
threat to normal functioning of an organism. In the structure of orphan diseases the problem of respiratory disorders, which can be the first signs of such diseases, is most acute for children with mucopolysaccharidoses [1]-[3].

Mucopolysaccharidoses are a group of rare lysosomal storage diseases, connected with lack of enzymes, involved in the catabolism of mucopolysaccharides_-glucosaminoglycans (GAG). Depending on the severity of the disease the symptoms of respiratory disorders can range from slight to severe [4] [5].

First disease symptoms manifest after the first year of life and include frequent virus respiratory infections, recurrent otitis, rhinitis, and abdominal hernia. At age of 2 nostrils and lips thickening, macroglossia, and growth retardation appear. General signs of the disease are macrocephaly, short neck and torso. A diseased baby's face obtains coarse features (gargoylism). In 3 - 4 years old motor coordination disturbance is developed, behavior changes, and aggressiveness appears. At older ages there appear deafness, joint stiffness, contractures of large and small joints, as well as atypical retinitis pigmentosa and corneal opacity [4]-[7].

So-called "gargoyle-like phenotype" in patients with mucopolysaccharidoses is formed from different (typical only for them) structural features, which among other things contribute to the development of respiratory disorders:

1) a wide nose with a flat nose bridge; 2) short and narrow nasal passages; 3) a short neck; 4) large rare teeth; 5) macroglossia; 6) gingival hyperplasia; 7) enlarged tonsils and adenoids; 8) abnormalities of vertebrae cervicales due to disturbance of ossification and osteogenesis; 9) highly located epiglottis; 10) overgrowth of arytenoid cartilage and aryepiglottic folds tissue; 11) deformation of chest and ribs; 12) tracheal wall irregularities and thickening [8]-[10].

Thus, clinical displays of respiratory disorders associated both with the above-mentioned pathology of skull and spine bones and directly with the accumulation of GAGs in tissues of the upper and lower respiratory tract [2] [10] [11].

Noisy, wheezing breathing is typical for children with MPS and it usually persists even in the absence of respiratory infection in a child. Increased secretion of mucus in upper and lower airway increases the obstruction, aggravating the patient's condition [12].

In connection with such changes in a child with MPS, accompanied with SARS, a protracted inflammatory process in a respiratory tract (aggravated by pneumonia or bronchial obstruction syndrome) is highly possible.

Breathing process is carried out under regulating control of nervous system, and changes in brain and spinal cord also affect respiratory disorder in children with MPS. Combined impact of changes in breathing regulation mechanism and airway abnormalities can lead to respiratory insufficiency, aggravated during sleep [9] [13].

According to modern research data, $80 \%$ of patients with MPS suffer from respiratory disorder during sleep. Respiratory disorders during sleep can be classified as obstructive sleep syndrome (OSAS) [2] [10] [14].

Two forms of MPS development are distinguished-slight and severe. At severe form a patient has all the symptoms with severe disturbance of cognitive and mental functions; death occurs in the second decade of a patient's life. At slight form a late debut of the disease (in adolescence or even early adulthood) is possible; mental retardation is slightly expressed or absent; patients often live to 30 years old.

Data, accumulated over the past 10 years, evidence that obstructive sleep apnea increases the risk of death from cardiovascular diseases and can be an independent risk factor for sudden cardiac death of this group of patients [10] [12]-[14].

The aim of our study is to determine the prevalence of OSAS and the dynamics of its course changes, depending on severity of various organs affection in children with MPS II.

\section{Materials and Methods}

For the analysis of respiratory disturbances during sleep in children with MPS we carried out cardiorespiratory monitoring of day or night sleep, using Embla N7000 polysomnography complex, as well as Apnea Link portable device and MiROxi pulse oximeter. Night cardiorespiratory monitoring included ECG, determination of saturation and nasal flow pressure, thoracic and abdominal wall movements (total time of examination was 6 hours). The method allows to identify associations between respiratory disorders and heart rhythm, to assess main indicators of respiratory disorders during sleep, followed by the prevention of life-threatening conditions in children with MPS.

The study included 17 children aged from 1.5 to 15 years old (boys, mean age is $12.5 \pm 3.9$ years old), under- 
going planned examination and treatment in the Research Institute of Preventive Pediatrics and Rehabilitation Treatment of Federal State Budgetary Institution "Scientific Centre of Children Health" under the Russian Academy of Medical Sciences from 2009 to 2012. Hunter syndrome was displayed in slight form in 7 children, severe form-in 10 children. Distribution according to forms was performed in accordance with presence or absence of preserved intelligence.

At the moment of inclusion to the study absence or slight respiratory disorder were diagnosed in equal numbers of patients (25\% and $25 \%$, respectively) with a slight form of MPS. At severe form there was established the predominance of moderate-to-severe and severe respiratory disorders (33.3\% and $44.4 \%$, respectively). Hypertrophy of adenoids was determined in every second patient with slight and severe disease form of disease.

Clinical characteristics of slight and severe forms of mucopolysaccharidoses II in examined patients are presented in Table 1.

\section{Key Cardiovascular Indicators}

In order to assess the severity of respiratory disturbances during sleep, we used the following basic concepts of night sleep monitoring: 1) Apnea is respiratory standstill with complete cessation of airflow into the airway not less than for 10 seconds; 2) Hypopnea is decrease of respiratory flow by $50 \%$ or more, accompanied by a decrease of blood saturation with oxygen by $4 \%$ or more; 3 ) apnoea-hypopnoea index (AHI) is a number of episodes of significant apnea/hypopnea during 1 hour of sleep; 4) desaturation index (DI) is a number of reductions of saturation of blood oxyhemoglobin with oxygen more than by $4 \%$, associated with episodes of respiratory disorder for 1 hour of sleep.

OSAS severity was assessed by apnea-hypopnea index (AHI). There were distinguished three degrees of OSAS severity: slight form at AHI of $1.5-5 / \mathrm{h}$, a moderate form at AHI of $5-10 / \mathrm{h}$ and severe form at AHI of over 10/h [14].

\section{Results}

AHI, $\mathrm{SpO}_{2}$ and DI indicators were studied in 17 children with mucopolysaccharidoses II (Hunter Syndrome). Obstructive sleep apnea syndrome (AHI > 1.5) was diagnosed in 10 cases (58.8\%): slight (AHI is of 1.5 - 5) -in 4 patients (23.5\%), moderate (AHI is of 5 - 10) -in 4 patients (23.5\%), severe (AHI is over 10) -in 2 patients (11.8\%). AHI median with Hunter syndrome was $5.3 \pm 6.9$ /hour. OSAS was absent in 7 children (41.2\%). Body mass index (BMI) median was $19.6 \pm 3.6 \mathrm{~kg} / \mathrm{m}^{2}\left(12.9\right.$ - 28.2). Median of blood saturation with oxygen $\left(\mathrm{SpO}_{2}\right)$ was $87.5 \% \pm 10.6 \%$, desaturation index (DI) was $10.4 \pm 13.3 / \mathrm{h}$; number of patients with $\mathrm{SpO}_{2}<95 \%$ was $76.4 \%$ (13 children).

\begin{tabular}{|c|c|c|}
\hline \multirow[b]{2}{*}{ Forms } & \multicolumn{2}{|c|}{ Clinical forms } \\
\hline & Slight $(n=7)$ & Severe $(n=10)$ \\
\hline \multicolumn{3}{|l|}{ Age } \\
\hline 1 - 3 years old & 5 & - \\
\hline 4 - 7 years old & 1 & 6 \\
\hline$>7$ years old & 1 & 4 \\
\hline Respiratory disorders & 5 & 9 \\
\hline Absence & 2 & 1 \\
\hline Slight & 2 & 2 \\
\hline Moderate & 3 & 3 \\
\hline Severe & - & 4 \\
\hline Adenoids hypertrophy & 4 & 5 \\
\hline
\end{tabular}


OSAS was absent in children aged from 1 to 3 years old, in the group of children from 4 to 7 years old patients with slight form of OSAS (43\%-3 of 7) dominated. In the group of children older than 7 years oldmoderate severity of OSAS was found in $60 \%$ of patients ( 3 out of 5), severe form-in $40 \%$ of cases (2 of 5 ) (see Table 2).

Apnoea-hypopnoea index medians in the group of children older than 7 years old (10.9 \pm 9.4/hour) significantly exceeded $(\mathrm{p}<0.05)$ AHI medians of patients of younger age group $(1-3$ years $)-0.8 \pm 0.3 /$ hour. In patients of preschool group ( 4 - 7 years old) AHI medians were $4.3 \pm 4.8$ /hour (Table 2).

There were not found reliable differences between medians of $\mathrm{SpO}_{2}$ and an average number of reductions of saturation of blood oxyhemoglobin with oxygen (DI) in these age groups (Table 3). At that $\mathrm{SpO}_{2}$ medians in all age groups were below $95 \%$ ( 1 - 3 years old $-92.0 \% \pm 5.4 \%$; $4-7$ years old $-89.2 \% \pm 4.7 \%$; over 7 years old- $80.6 \% \pm 17.3 \%)$.

AHI medians in children with slight and severe forms of Hunter Syndrome were $1.9 \pm 1.9$ /h and $7.6 \pm 8.1$ / hour, without significant differences between groups $(\mathrm{p}>0.05)$ (Table 4). Nonetheless, it should be noted that in the group of children with slight form of disease patients without OSAS dominated (57.2\%—4 of 7), and at severe form of disease had moderate and severe OSAS (30\%-3/10, 40\%—4/10, respectively) (Table 4).

Table 2. Apnoea-hypopnoea index in children of different age groups with mucopolysaccharidoses II.

\begin{tabular}{ccccc}
\hline Apnoea-hypopnoea index & $\begin{array}{c}\mathbf{1}-\mathbf{3} \text { years old } \\
(\mathbf{n}=\mathbf{5})\end{array}$ & $\begin{array}{c}\mathbf{4}-\mathbf{7} \text { years old } \\
(\mathbf{n}=\mathbf{7})\end{array}$ & $\begin{array}{c}\text { Over 7 years old } \\
(\mathbf{n}=\mathbf{5})\end{array}$ & $\mathbf{p}$ \\
Median & $0.8 \pm 0.3$ & $4.3 \pm 4.8$ & $10.9 \pm 9.4$ & $\mathrm{p}^{\mathrm{A}}>0.05$ \\
Norm & $(0.6-1.3)$ & $(0.0-13.3)$ & $(4.4-27.5)$ & $\mathrm{p}^{\mathrm{B}}<0.05^{*} \mathrm{p}^{\mathrm{C}}>0.05$ \\
Slightly above the norm & $100 \%$ & $29.0 \%$ & - & $20.0 \%$ \\
Moderately above the norm & - & $43.0 \%$ & $60.0 \%$ \\
Significantly higher than the norm & - & $14.0 \%$ & $20.0 \%$ \\
\hline
\end{tabular}

${ }^{A} \mathrm{p}$ values when patients of younger age group are compared with patients of preschool group; ${ }^{\mathrm{B}} \mathrm{p}$ values when patients of younger age group are compared with patients older than 7 years old; ${ }^{C}$ p values when patients of preschool group are compared with patients older than 7 years old.

Table 3. Levels of blood saturation with oxygen and desaturation index in children different age groups with mucopolysaccharidoses II.

\begin{tabular}{|c|c|c|c|c|}
\hline Median & $\begin{array}{c}1 \text { - } 3 \text { years old } \\
(n=5)\end{array}$ & $\begin{array}{c}4 \text { - } 7 \text { years old } \\
(n=7)\end{array}$ & $\begin{array}{c}\text { over } 7 \text { years old } \\
(n=5)\end{array}$ & $\mathbf{p}$ \\
\hline $\mathrm{SpO}_{2}$ & $\begin{array}{c}92.0 \pm 5.4 \\
(84.0-97.6)\end{array}$ & $\begin{array}{c}89.2 \pm 4.7 \\
(85.5-97.0)\end{array}$ & $\begin{array}{c}80.6 \pm 17.3 \\
(51.0-92.0)\end{array}$ & $\begin{array}{l}\mathrm{p}^{\mathrm{A}}>0.05 \\
\mathrm{p}^{\mathrm{B}}>0.05 \\
\mathrm{p}^{\mathrm{C}}>0.05\end{array}$ \\
\hline DI & $\begin{array}{c}5.0 \pm 4.5 \\
(0.1-10.5)\end{array}$ & $\begin{array}{l}13.8 \pm 18.2 \\
(0.0-43.0)\end{array}$ & $\begin{array}{l}10.8 \pm 11.4 \\
(3.0-30.7)\end{array}$ & $\begin{array}{l}\mathrm{p}^{\mathrm{A}}>0.05 \\
\mathrm{p}^{\mathrm{B}}>0.05 \\
\mathrm{p}^{\mathrm{C}}>0.05\end{array}$ \\
\hline
\end{tabular}

${ }^{A} p$ values when patients of younger age group are compared with patients of preschool group; ${ }^{B} \mathrm{p}$ values when patients of younger age group are compared with patients older than 7 years old; ${ }^{\mathrm{C}} \mathrm{p}$ values when patients of preschool group are compared with patients older than 7 years old.

Table 4. Apnoea-hypopnoea index levels in children with slight and severe forms of mucopolysaccharidoses II.

\begin{tabular}{cccc}
\hline \multicolumn{1}{c}{ AHI value } & Slight form $(\mathbf{n}=7)$ & p & Severe form $(\mathbf{n}=\mathbf{1 0})$ \\
\hline Median & $1.9 \pm 1.9(0.4-5.8)$ & $>0.05$ & $7.6 \pm 8.1(0.0-27.5)$ \\
Norm & $57.2 \%$ & $10.0 \%$ \\
Slightly above the norm & $23.5 \%$ & $30.0 \%$ \\
Moderately above the norm & $14.3 \%$ & $40.0 \%$ \\
Significantly higher than the norm & $28.5 \%$ &
\end{tabular}


Medians of $\mathrm{SpO}_{2}$ (slight form-91\% $\pm 4.7 \%$, severe form-89.2\% $\pm 4.7 \%$ ) and DI (slight form-4.3 \pm 3.9/hour, severe form-89.2 $\pm 4.7 /$ hour) did not significantly differ between the two groups (Table 5). Overwhelming number of patients of both groups showed $\mathrm{SpO}_{2}$ below $95 \%$ (patients with slight form-in $71.4 \%$ of cases (5 of 7), with severe form-in $80 \%$ of cases (8 of 10)).

We determined $\mathrm{AHI}, \mathrm{SpO}_{2}$ and DI medians in children with tracheo-bronchial tree affections (Table 6). Every second child with severe respiratory disorders severe displays of OSAS was noted. $\mathrm{SpO}_{2}$ medians of about $95 \%$ were observed only in the group of children without respiratory disorders (95.2\% $\pm 3.6 \%)$, in other groups they were $91.5 \% \pm 2.9 \%, 88.7 \% \pm 4.7 \%, 76.0 \% \pm 17.1 \%$ (slight, moderate and severe respiratory disorders, respectively). DI medians increased along with an increase of the severity of respiratory disorders.

Our study showed significant differences $(\mathrm{p}<0.05)$ (Table 6) between $\mathrm{AHI}$ and $\mathrm{SpO}_{2}$ indicators in groups of children without and with moderate respiratory disorders. And between DI indicators in groups of children without and with slight respiratory disorders, without and with moderate respiratory disorders, as well as without and with severe respiratory disorders (DI medians are $0.6 \pm 0.8 / \mathrm{h}, 2.5 \pm 1.2 / \mathrm{h}, 7.3 \pm 2.9 / \mathrm{h}, 30.2 \pm 14.2 / \mathrm{h}$, respectively).

We have studied the effect of adenoids hypertrophy on $\mathrm{AHI}, \mathrm{SpO}_{2}$ and DI indicators in children with Hunter Syndrome. OSAS was detected in 5 of 9 cases (58.8\%) in children with adenoids hypertrophy: slight form—in 2 patients (22.2\%), moderate form—in 2 patients (22.2\%), severe form—in 1 patient (11.1\%) (see Table 7). 4 of 9 children with adenoids hypertrophy did not have OSAS (44.5\%). AHI median in the group was $6.7 \pm 9.0 /$ hour (Table 7).

$37.5 \%$ of children (3 of 8) without adenoids hypertrophy did not have OSAS, an equal number of children had slight and moderate OSAS—25\% each (2 of 8); AHI median in this group was $3.9 \pm 4.4 / \mathrm{h}$ (Table 9). There were defined medians of $\mathrm{SpO}_{2}$ and DI for each group: $89.3 \% \pm 4.8 \%$ and $13.4 \pm 14.5 /$ hour, $85.6 \% \pm 15.0 \%$ and $7.0 \pm$ 10.1/hour (with and without adenoids hypertrophy, respectively) (Table 8).

Table 5. Blood saturation with oxygen levels in children with slight and severe forms of mucopolysaccharidoses II.

\begin{tabular}{cccc}
\hline Median & Slight form $(\mathbf{n}=7)$ & $\mathbf{p}$ & Severe form $(\mathbf{n}=\mathbf{1 0})$ \\
\hline $\mathrm{SpO}_{2}$ & $91.2 \pm 4.7(84.0-97.6)$ & $>0.05$ & $85.0 \pm 13.0(51.0-97.0)$ \\
DI & $4.3 \pm 3.9(0.1-10.5)$ & $>0.05$ & $14.6 \pm 16.0(0.0-43.0)$ \\
\hline
\end{tabular}

Table 6. Comparison of Apnoea-hypopnoea index AHI, blood saturation with oxygen (\%) and desaturation index, depending on the severity of respiratory disorders and their absence in children with mucopolysaccharidoses II.

\begin{tabular}{|c|c|c|c|c|c|}
\hline & Norm & Slight & Moderate & Severe & $\mathbf{p}$ \\
\hline AHI & $0.9 \pm 0.3$ & $2.1 \pm 2.0$ & $6.2 \pm 4.8$ & $10.4 \pm 11.9$ & $\begin{array}{l}\mathrm{p}^{\mathrm{A}}>0.05 \\
\mathrm{p}^{\mathrm{B}}<0.05^{*} \\
\mathrm{p}^{\mathrm{C}}>0.05 \\
\mathrm{p}^{\mathrm{D}}>0.05 \\
\mathrm{p}^{\mathrm{E}}>0.05 \\
\mathrm{p}^{\mathrm{F}}>0.05\end{array}$ \\
\hline $\mathrm{SpO}_{2}$ & $95.2 \pm 3.6$ & $91.5 \pm 2.9$ & $88.7 \pm 4.7$ & $76.0 \pm 17.1$ & $\begin{array}{l}\mathrm{p}^{\mathrm{A}}>0.05 \\
\mathrm{p}^{\mathrm{B}}<0.05^{*} \\
\mathrm{p}^{\mathrm{C}}>0.05 \\
\mathrm{p}^{\mathrm{D}}>0.05 \\
\mathrm{p}^{\mathrm{E}}>0.05 \\
\mathrm{p}^{\mathrm{F}}>0.05\end{array}$ \\
\hline DI & $0.6 \pm 0.8$ & $2.5 \pm 1.2$ & $7.3 \pm 2.9$ & $30.2 \pm 14.2$ & $\begin{array}{c}\mathrm{p}^{\mathrm{A}}<0.05^{*} \\
\mathrm{p}^{\mathrm{B}}<0.05^{*} \\
\mathrm{p}^{\mathrm{C}}<0.05^{*} \\
\mathrm{p}^{\mathrm{D}}>0.05 \\
\mathrm{p}^{\mathrm{E}}>0.05 \\
\mathrm{p}^{\mathrm{F}}>0.05\end{array}$ \\
\hline
\end{tabular}

\footnotetext{
${ }_{\mathrm{A}}^{\mathrm{A}}$ values when comparing groups of patients without and with slight respiratory disorders; ${ }^{\mathrm{B}} \mathrm{p}$ values when comparing groups of patients without and with moderate respiratory disorders; ${ }^{C}$ p values when comparing groups of patients without and with severe respiratory disorders; ${ }^{\mathrm{D}} \mathrm{p}$ values when comparing groups of patients with slight and moderate respiratory disorders; ${ }^{\mathrm{E}} \mathrm{p}$ values when comparing groups of patients with slight and severe respiratory disorders; ${ }^{\mathrm{F}} \mathrm{p}$ values when comparing groups of patients with moderate-to-severe and severe respiratory disorders.
} 
Table 7. Apnoea-hypopnoea index levels, depending on presence or absence of adenoids hypertrophy in children with mucopolysaccharidoses II.

\begin{tabular}{|c|c|c|c|}
\hline Apnoea-hypopnoea index & $\begin{array}{l}\text { Without hypertrophy } \\
(\mathbf{n}=\mathbf{8})\end{array}$ & $\mathbf{p}$ & $\begin{array}{c}\text { Hypertrophy of } 2 \text { - } 3 \text { degree } \\
((n=9)\end{array}$ \\
\hline Median & $3.9 \pm 4.4(0.0-27.5)$ & $>0.05$ & $6.7 \pm 9.0(0.4-13.3)$ \\
\hline Norm & $37.5 \%$ & & $44.5 \%$ \\
\hline Slightly above the norm & $25.0 \%$ & & $22.2 \%$ \\
\hline Moderately above the norm & $25.0 \%$ & & 22.2 \\
\hline Significantly higher than the norm & $12.5 \%$ & & 11.1 \\
\hline
\end{tabular}

Table 8. Levels of blood saturation with oxygen and desaturation index, depending on presence or absence of adenoids hypertrophy in children with mucopolysaccharidoses II.

\begin{tabular}{cccc}
\hline Median & $\begin{array}{c}\text { Without hypertrophy } \\
\mathbf{( n = 8 )}\end{array}$ & $\mathbf{p}$ & $\begin{array}{c}\text { Hypertrophy of 2 }-\mathbf{3} \text { degrees } \\
(\mathbf{n}=\mathbf{9})\end{array}$ \\
\hline $\mathrm{SpO}_{2}$ & $85.6 \pm 15.0(51.0-97.6)$ & $>0.05$ & $89.3 \pm 4.8(84.0-97.0)$ \\
DI & $7.0 \pm 10.1(0.1-30.7)$ & $>0.05$ & $13.4 \pm 14.5(0.0-43.0)$ \\
\hline
\end{tabular}

Table 9. Comparison of Apnoea-hypopnoea index, blood saturation with oxygen and desaturation index $(\mathrm{M} \pm \sigma)$ in patients with Hunter Syndrome, depending on presence or absence of ERT at the moment of the first examination.

\begin{tabular}{cccc}
\hline Therapy & AHI & $\mathbf{S p O}_{2}$ & DI \\
\hline Therapy “+” (n= 13) & $6.2 \pm 7.5$ & $85.7 \pm 11.5$ & $12.4 \pm 14.5$ \\
$\mathbf{p}$ & $>0.05$ & $>0.05$ & $>0.05$ \\
$\begin{array}{c}\text { Therapy “+” ( }=\mathbf{4}) \\
\text { (7 months - 12 month) }\end{array}$ & $2.2 \pm 1.6$ & $93.4 \pm 4.2$ & $3.90 \pm 3.9$ \\
\hline
\end{tabular}

Comparison of $\mathrm{AHI}, \mathrm{SpO}_{2}$ and DI medians did not reveal the influence of adenoids hypertrophy on OSAS severity (approximately equal percentage of slight, moderate and severe OSAS among groups), no significant differences of $\mathrm{SpO}_{2}$ and ID indicators between groups were found ( $>$ > 0.05) (Table 8).

At the moment of the first examination four children with Hunter Syndrome were receiving enzyme replacement therapy (ERT) for 1 year (Elapraza medicine, Shire Human Genetic Therapies Inc., Cambridge, MA), 13 children were examined for the first time prior to ERT, significant differences in $\mathrm{AHI}, \mathrm{SpO}_{2}$ and ID between groups were not obtained ( $p>0.05$ ), which can be explained by insufficient duration of ERT (Table 9).

Two children with severe Hunter Syndrome were re-examined after two years from the beginning of ERT treatment. The first patient (11 years old) showed a significant positive trend of $\mathrm{AHI}, \mathrm{SpO}_{2}$ and ID indicators changing (before treatment $\mathrm{AHI}$ was 4.4, $\mathrm{SpO}_{2}-88 \%$, in 2 years- $\mathrm{AHI}$ was 0.6, $\mathrm{SpO}_{2}-95.6 \%$ ); the second patient (8 years old) showed no dynamics, due to the absence of OSAS prior and during ERT treatment (before therapy AHI was 0.8, $\mathrm{SpO}_{2}-97 \%$, in 2 years $\mathrm{AHI}$ was $0.0, \mathrm{SpO}_{2}-95 \%$ ).

The positive effect of enzyme replacement therapy was shown during 6-minute walk test, as well as during the evaluation of lung function with the help of external respiration function (ERF).

Treatment of respiratory disorders in children with MPS II, aggravated by respiratory infection, involves the use of topical medication for the reduction of inflammation. Quite often it is necessary to perform an adenoand/or tonsillectomy. However, in severe cases, these operations can not be performed due to potential complications after anesthesia and surgery [15].

Severe respiratory disorder during sleep can be treated by continuous positive applied pressure (CPAP), during which air is injected under high pressure through a mask, thus preventing airway collapse during inspiration, increasing sleep quality, decreasing shortness of breath and normalizing concentration of blood gases [16] [17]. 


\section{Conclusions}

Thus, obstructive sleep apnea syndrome (OSAS) was detected in more than half of patients (58.8\%) with mucopolysaccharidoses II (in equal number of children with slight and moderate-to-severe OSAS over (23.5\%), AHI was of $5.3 \pm 6.9 / \mathrm{h}$ ). Our data in most points are consistent with the data of previously published studies (Leighton S. E. et al.) [10] [16] [17].

In the group of infants ( 1 - 3 years old) slight form of OSAS (AHI was $0.8 \pm 0.3 / h$ ) dominated, whereas in the adolescent group - severe form (AHI was $10.9 \pm 9.4 / \mathrm{h}$ ). Aggravation of OSAS with aging is possibly connected with the progression of the disease itself, which can be caused by many factors, including the distribution of glycosaminoglycans deposits in tracheobronchial tree mucous.

The severity of OSAS also depended on:

-the form of disease (at slight form patients with without OSAS dominated (57.2\%), at severe form patients had OSAS of moderate and severe form- $30 \%$ and $40 \%$, respectively).

-respiratory disorder severity (in case of their absence OSAS was not determined (AHI $0.9 \pm 0.3 / \mathrm{h}$ ), while at moderate-to-severe disorders moderate form of OSAS was revealed (AHI $6.2 \pm 4.8 / \mathrm{h}, \mathrm{p}<0.05$ ).

$\mathrm{SpO}_{2}$ indicator in children with mucopolysaccharidoses II amounted to $87.5 \pm 10.6 \%$ (the number of patients with $\mathrm{SpO}_{2}$ below $95 \%$ was $76.4 \%$ ), only in the group of children without respiratory disorders its average value was normal $(95.2 \% \pm 3.6 \%)$. In this very group minimum value of DI was defined $(0.6 \pm 0.8 / \mathrm{h})$, which significantly differed from DI in the groups of patients with slight, moderate and severe respiratory disorders (DI: 2.5 $\pm 1.2 / \mathrm{h}, 7.3 \pm 2.9 / \mathrm{h}, 30.2 \pm 14.2 / \mathrm{h}$ ).

Thus, the high frequency of respiratory disorders in patients with MPS, their severity and display at the beginning of the main disease proves the importance of timely evaluation and follow-up. Cardiorespiratory monitoring is necessary to identify children with moderate-to-severe and severe forms of OSAS with subsequent prevention of life-threatening conditions, the occurrence of which is possible at this disorder.

\section{References}

[1] Muhlebach, M.S., Wooten, W. and Muenzer, J. (2011) Respiratory Manifestations in Mucopolysaccharidoses. Paediatric Respiratory Reviews, 12, 133-138. http://dx.doi.org/10.1016/j.prrv.2010.10.005

[2] Semenza, G.L. and Pyeritz, R.E. (1988) Respiratory Complications of Mucopolysaccharide Storage Disorders. Medicine (Baltimore), 67, 209-219. http://dx.doi.org/10.1097/00005792-198807000-00002

[3] Nashed, A., Al-Saleh, S., Gibbons, J., et al. (2009) Sleep-Related Breathing in Children with Mucopolysaccharidosis. Journal of Inherited Metabolic Disease, 32, 544-550. http://dx.doi.org/10.1007/s10545-009-1170-4

[4] Martin, R., Beck, M., Eng, C., Giurliani, R., Harmatz, P., et al. (2008) Recognition and Diagnosis of Mucopolysaccharidosis II (Hunter Syndrome). Pediatrics, 121, e377-e386. http://dx.doi.org/10.1542/peds.2007-1350

[5] Muenzer, J., Beck, M., Eng, C.M, et al. (2011) Long-Term, Open-Labeled Extension Study of Idursulfase in the Treatment of Hunter Syndrome. Genetics in Medicine, 13, 95-101. http://dx.doi.org/10.1097/GIM.0b013e3181fea459

[6] Muenzer, J. (2011) Overview of the Mucopolysaccharidoses. Rheumatology (Oxford), 50, v4-v12. http://dx.doi.org/10.1093/rheumatology/ker394

[7] Muenzer, J., Beck, M., Eng, C., et al. (2009) Multidisciplinary Management of Hunter Syndrome. Pediatrics, 124, 1228-1239. http://dx.doi.org/10.1542/peds.2008-0999

[8] Shih, S.L., Lee, Y.J., Lin, S.P., Sheu, C.Y. and Blickman, J.G. (2002) Airway Changes in Children with Mucopolysaccharidoses. Acta Radiologica, 43, 40-43. http://dx.doi.org/10.1034/j.1600-0455.2002.430108.x

[9] Giugliani, R., Harmatz, P. and Wraith, J.E. (2007) Management Guidelines for Mucopolysaccharidosis VI. Pediatrics, 120, 405-418. http://dx.doi.org/10.1542/peds.2006-2184

[10] Leighton, S.E.J., Papsin, B., Vellodi, A., Dinwiddie, R. and Lane, R. (2001) Disordered Breathing during Sleep in Patients with Mucopolysaccharidoses. International Journal of Pediatric Otorhinolaryngology, 58, 127-138. http://dx.doi.org/10.1016/S0165-5876(01)00417-7

[11] Leboulanger, N., Louis, B., Vialle, R., et al. (2011) Analysis of the Upper Airway by the Acoustic Reflection Method in Children with Mucopolysaccharidosis. Pediatric Pulmonology, 46, 587-594. http://dx.doi.org/10.1002/ppul.21409

[12] Berger, K.I., Fagondes, S.C., Giugliani, R., et al. (2013) Respiratory and Sleep Disorders in Mucopolysaccharidoses. Journal of Inherited Metabolic Disease, 36, 201-210. http://dx.doi.org/10.1007/s10545-012-9555-1

[13] Lin, H.Y., Chen, M.R., Lin, C.C., et al. (2010) Polysomnographic Characteristics in Patients with Mucopolysaccharidoses. Pediatric Pulmonology, 45, 1205-1212. http://dx.doi.org/10.1002/ppul.21309 
[14] Kamin, W. (2008) Diagnosis and Management of Respiratory Involvement in Hunter Syndrome. Acta Paediatrica Supplement, 97, 57-60. http://dx.doi.org/10.1111/j.1651-2227.2008.00650.x

[15] Jeong, H.S., Cho, D.Y., Ahn, K.M. and Jin, D.K. (2006) Complications of Tracheotomy in Patients with Mucopolysaccharidoses Type II (Hunter Syndrome). International Journal of Pediatric Otorhinolaryngology, 70, 1765-1769. http://dx.doi.org/10.1016/j.ijporl.2006.05.021

[16] Ginzburg, A.S., Önal, E., Aronson, R.M., Schild, J.A., Mafee, M.F. and Lopata, M. (1990) Successful Use of NasalCPAP for Obstructive Sleep Apnea in Hunter Syndrome with Diffuse Airway Involvement. Chest, 97, 1496-1498. http://dx.doi.org/10.1378/chest.97.6.1496

[17] Yeung, A.H., Cowan, M.J., Horn, B. and Rosbe, K.W. (2009) Airway Management in Children with Mucopolysaccharidoses. Archives of Otolaryngology—Head Neck Surgery, 135, 73-79. http://dx.doi.org/10.1001/archoto.2008.515

\section{Abbreviations}

AHI: Apnoea-hypopnoea index.

OSAS: Obstructive sleep apnea syndrome.

$\mathrm{SpO}_{2}$ : Blood saturation with oxygen.

DI: Desaturation index.

MSP: Mucopolysaccharidoses.

BMI: Body mass index. 